\title{
The Samsung story
}

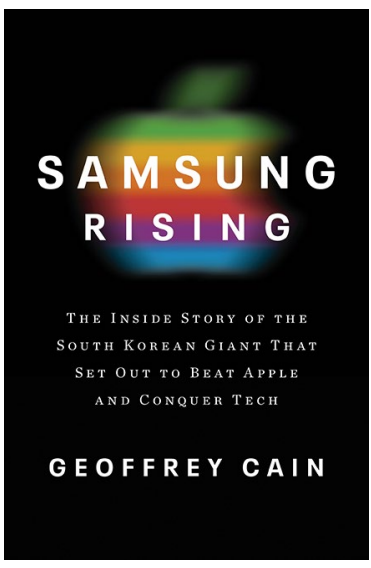

Samsung
Rising

Geoffrey Cain

CURRENCY:

2020. 416 PP.

$\$ 29$

C amsung was founded in 1938 as a small company dealing in dried fish and noodles. It entered the electronics industry in the late 1960s, and today is the largest manufacturer of smartphones, televisions and memory chips in the world. In Samsung Rising: The Inside Story of the South Korean Giant That Set Out to Beat Apple and Conquer Tech, Geoffrey Cain provides an exposé of this secretive company. Drawing on interviews with Samsung employees and market watchers, Cain - an American journalist who has reported on Samsung for more than ten years - explores the company's culture, products, successes and failures. The book charts the rise of the global technology giant, and examines its influence on the international technology industry and the politics and culture of South Korea.

Cain calls Samsung a "strange labyrinth of a company" and his engaging book reads like a dynastic story covering three generations of the Lee family. In 1938, Lee Byung-chul dropped out of college and founded a small business he named Samsung Trading Co. The initial corporate logo had three stars and was based on a graphical representation of the Korean Hanja word Samsung. Byung-chul was inspired by Mitsubishi and created a family-centric (chaebol) management structure for the company. Samsung behaved much like a traditional
Japanese company, where executives did as they were told without argument. This corporate behaviour, together with help from the government, allowed the company to grow quickly, expanding into sugar refining, media, textiles and insurance - Samsung was considered an economic miracle. Following a fight over inheritance, Byung-chul was succeeded by his third son Lee Kun-hee in 1987. Kun-hee invested heavily in semiconductor technologies and transformed Samsung from a manufacturer into a global technology powerhouse. In 2014, he was hospitalized with a heart attack, which left him in a coma. Since then, his son Lee Jae-yong - who is regarded as more easy-going than his predecessors - has served as the de facto head of the company.

Cain provides some intriguing insight into the management and technology at Samsung. The executives and the company appear to exist - and thrive - in a state of permanent crisis, suffering political corruption and sex scandals. Samsung's leaders have been in and out of the courts due to tax evasion allegations, financial mismanagement, destruction of evidence, and improper sales of stocks, and Jae-yong was arrested in 2017 over charges linked to a scandal involving South Koreass then president, Park Geun-hye.

At the same time, during Jae-yong's administration, Samsung has sold non-core assets and invested profits in new technologically promising areas, including semiconductors (beyond memory), 5G, software, quantum dot technologies and artificial intelligence chips. The company's biggest success in the past decade has been its smartphone division, where they currently hold the highest global market share. But this success has not been without its setbacks. In 2017, battery defects caused Galaxy Note 7 devices to catch fire, creating a major safety hazard for the public and leading to recalls. Remarkably, throughout all of these crises, the company has continued to grow and has remained profitable due to its largely diversified business.
Cain's book also analyses the relationship between Samsung and Apple. Steve Jobs visited Samsung in 1983 looking for displays and memory chips in order to build a tablet computer. Samsung subsequently supplied Apple with displays, chips and other components, which have been used in devices such as the iPhone and iPad. But a patent battle began in 2011. Apple claimed that Samsung had copied the iPhone, leading to a long-running series of lawsuits that were only finally resolved in 2018, with Apple being awarded US $\$ 539$ million. Issues between the two companies continue, and they are now perhaps best described as 'frenemies'.

For Samsung Rising, Cain interviewed more than 400 people, including retired Samsung executives and aides, consultants, battery-explosion investigators, suppliers, distant relatives and foreign veterans of the company. The detailed discussion and a rich vein of anecdotes are the book's key contribution to the literature on Samsung. One crucial aspect highlighted by Cain is Samsung's cultural power: the technology of the company touches everything in South Korea and, for many, the country is the 'Republic of Samsung'. And it is the nation's vested interest in the company that is the difference between Samsung and other electronics companies. There is, though, a dark side to this relationship, which can expose the company to political manipulations that go beyond commercial standards and expectations.

Cain's book is an essential read for anyone who wants to know more about the technology giant Samsung, but also for those who want insight into chaebol corporate culture, management philosophy and modern technology.

\section{Reviewed by Ye Zhou $\bowtie$ \\ Institute for Advanced Study, Shenzhen University, Shenzhen, China.

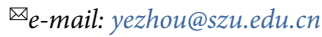

Published online: 22 May 2020

https://doi.org/10.1038/s41928-020-0418-8 